\title{
Resolução Lamelar num Novo Microscópio Eletrônico de Varredura
}

\author{
Hans-J ürgen Kestenbach, Nádia C. P. S. Nocite, Rinaldo Gregório F , J oachim Loos e J ürgen Petermann
}

Resumo: Trabalhando com elétrons de baixa energia (na faixa de $1 \mathrm{keV}$ ), o novo microscópio eletrônico de varredura dispensa a etapa de metalização e permite a observação direta da estrutura lamelar de polímeros semicristalinos, sem a necessidade de preparação de amostras. São apresentados exemplos da morfologia lamelar do PVDF em função das condições de processamento e da temperatura de cristalização, em filmes contendo as fases $\alpha, \beta$ e $\gamma$. Um outro exemplo revela o crescimento inicial da camada transcristalina que se formou ao longo de uma fibra de polietileno de ultra-alto peso molecular embutida em matriz de polietileno de alta densidade.

Palavras-chave: Resolução lamelar, microscopia eletrônica de varredura, estrutura supramolecular, transcristalinidade.

\section{Introdução}

Um novo tipo de microscópio eletrônico de varredura (MEV), projetado especialmente para operação em baixa voltagem (MEVBV), tem facilitado a observação de morfologias lamelares em polímeros semicristalinos. Tradicionalmente, o microscópio eletrônico de transmissão precisava ser utilizado quando se procurava informações morfológicas a respeito de estruturas lamelares. Contudo, a técnica de transmissão exige métodos especiais de preparação de amostras que sempre envolvem o risco de gerar estruturas diferentes daquelas que estão sendo investigadas. Como exemplos, poderiam ser citadas morfologias danificadas pelo corte no ultramicrótomo, morfologias modificadas pelo ataque ou pelo tingimento químico, e finalmente morfologias pouco representativas em filmes finos preparados a partir de soluções diluídas ${ }^{1}$. No MEVBV, por outro lado, nenhum cuidado particular é necessário na preparação das amostras, e a estrutura superficial do polímero pode ser investigada de maneira direta e com alta resolução. Os melhores resultados tem sido encontrados com amostras em forma de filmes semifinos (espessuras na faixa de $\mu \mathrm{m}$ ), uma vez que, neste caso, o recobrimento para condutividade elétrica pode ser dispensado, oferecendo o acesso direto à superfície original da amostra. Uma outra vantagem é a facilidade com que uma determinada região de interesse na amostra pode ser escolhida e localizada em baixo aumento. Desta maneira, por exemplo, esferulitos podem ser fotografados no microscópio ótico, e posteriormente identificados no microscópio eletrônico para um estudo mais detalhado da sua estrutura lamelar.

Neste artigo, destacamos o crescimento lamelar das diversas fases do polifluoreto de vinilideno (PVDF) e a formação de camadas transcristalinas de

Hans-Jürgen Kestenbach, Nádia C. P. S. Nocite e Rinaldo Gregório Filho, Universidade Federal de São Carlos - Departamento de Engenharia de Materiais , Caixa Postal 676, 13565-905, São Carlos, SP; Joachim Loos e Jürgen Petermann, Universidade de Dortmund, Alemanha, Lehrstuhl für Werkstoffkunde 
polietileno de alta densidade (PEAD) ao longo de fibras de polietileno de ultra-alto peso molecular (PEUAPM), com o objetivo de demonstrar as principais vantagens do MEVBV. Além disso, são apresentados os princípios básicos de operação do novo microscópio.

\section{Microscopia de Varredura a Baixa Voltagem}

Teoricamente, os benefícios oferecidos pela operação do microscópio eletrônico de varredura a baixa voltagem tem sido conhecidos por muito tempo. Quanto menor for a energia dos elétrons incidentes, menor será o volume de interação destes com a amostra. Para um potencial de aceleração de $1 \mathrm{keV}$, por exemplo, o volume de interação atinge dimensões comparáveis ao tamanho do feixe incidente na superfície da amostra (que pode estar na faixa de $10 \mathrm{~nm}$ ou menor). Com isto, diminui a fração daqueles elétrons secundários que são criados por elétrons retroespalhados e que, geralmente, são emitidos em lugar distante da posição momentânea do feixe incidente. Em consequiência, a resolução real do microscópio se aproxima de sua resolução teórica (diâmetro do feixe incidente), e o contraste entre detalhes superficiais da amostra melhora ${ }^{2}$. Nos microscópios tradicionais de varredura, no entanto, as vantagens teóricas desta operação à baixa voltagem não podem ser exploradas, devido à ineficiência das fontes termiônicas de elétrons quando operadas a baixa voltagem de aceleração, e também devido à falta de um sistema adequado de alto vácuo.

No caso dos filamentos convencionais de tungstênio ou de $\mathrm{LaB}_{6}$, a intensidade do feixe eletrônico aumenta linearmente com a voltagem de aceleração. A $1 \mathrm{keV}$, por exemplo, o brilho é apenas 5\% do seu valor a $20 \mathrm{keV}$. Por essa razão, o novo microscópio emprega um canhão de emissão de campo conhecido como FEG (Field Emission Gun), cujo brilho já ultrapassa as outras fontes por um fator de $100 \mathrm{em}$ condições normais de operação $(20 \mathrm{keV})$, e ainda diminui menos com o potencial de aceleração. Uma outra vantagem do canhão do tipo FEG é a sua "emissão a frio" que garante uma variação menor da energia dos elétrons, $\Delta \mathrm{E}$, em relação à emissão "a quente" dos canhões termiônicos ${ }^{3}$. Na operação de baixa voltagem, o valor de $\Delta \mathrm{E}$ se torna importante devido ao efeito da aberração cromática. Restringindo o limite de resolução proporcionalmente à relação $\Delta \mathrm{E} / \mathrm{E}$, a aberração cromática não compromete o desempenho das lentes eletromagnéticas durante a operação convencional dos microscópios de varredura, mas começa limitar o poder de resolução na operação à baixa voltagem (pequenos valores de $\mathrm{E}$ ).

O segundo ponto importante no projeto do MEVBV é o seu ultra-alto vácuo, garantindo valores na faixa de $10^{-9}$ Torr dentro da câmara de amostras. Este nível de vácuo torna-se necessário para evitar a contaminação na superfície da amostras, uma vez que elétrons de baixa energia seriam bloqueados por camadas convencionais de contaminação e não atingiriam a superfície original da amostra.

Neste trabalho foi utilizado um microscópio Hitachi modelo S-4500 e voltagens de aceleração entre 1 e $2 \mathrm{kV}$.

\section{Resolução Lamelar em Filmes de PVDF}

\section{Aplicações e Morfologia}

O polifluoreto de vinilideno (PVDF) possui uma gama muito grande de aplicações na indústria química, automobilística, elétrica, nuclear, agrícola, de alimento, farmacêutica e bioquímica. Porém, o que tornou esse polímero tão intensamente estudado nos últimos 20 anos foram as extraordinárias propriedades piro e piezoelétricas que ele apresenta. O PVDF exibe forte polimorfismo, com fases conhecidas como alfa, beta, gama e delta. Sob ponto de vista tecnológico, a fase beta, polar, é a de maior interesse por fornecer melhores propriedades piro e piezoelétricas. Para fins de aplicação, esta fase é obtida através do estiramento de filmes originalmente na fase alfa. Recentemente, foi verificado que na cristalização do PVDF a partir da solução em dimetilformamida (DMF) podem ser obtidas as fases alfa ou beta, em função da temperatura de cristalização escolhida ${ }^{4}$. O estudo da morfologia das diversas fases que o PVDF apresenta, e de sua influência nas propriedades elétricas, é de importância fundamental tanto científica como tecnológica. Tal estudo poderá elucidar dúvidas ainda existentes sobre os processos que ocorrem nesse material, responsáveis pela intensa polarização que ele pode reter e que, em última análise, resulta nas atividades piro e piezoelétricas do material. A causa principal dessa polarização ainda não é totalmente conhecida. Vários trabalhos teóricos tem sido desenvolvidos numa tentativa de explicar essa polarização em termos de cargas aprisionadas, e/ou da orientação cooperativa de dipolos existentes no material ${ }^{5-7}$. Contudo, tais teorias dependem de informações morfológicas, como tamanho e forma dos cristalitos 
presentes na amostra e alterações que a morfologia sofre no processo de estiramento. A técnica aqui apresentada, microscopia eletrônica de varredura a baixa voltagem, tem como principal vantagem no caso do PVDF a não necessidade de se preparar amostras em condições especiais de observação. Portanto, as mesmas amostras utilizadas para medidas elétricas, com espessuras entre 8 e $25 \mu \mathrm{m}$ e obtidas por solução ou a partir de fusão, podem ter as suas estruturas analisadas, independentemente de qualquer processo de preparação que possa alterar sua morfologia.

\section{Morfologia de Filmes Comerciais}

Filmes de PVDF são produzidos comercialmente pelas técnicas convencionais, tais como extrusão, laminação, moldagem por sopro e a partir de soluções. Uma sensível melhora nas propriedades dielétricas e piezoelétricas ocorre quando tais filmes são orientados, uni- ou bi-axialmente. As três primeiras

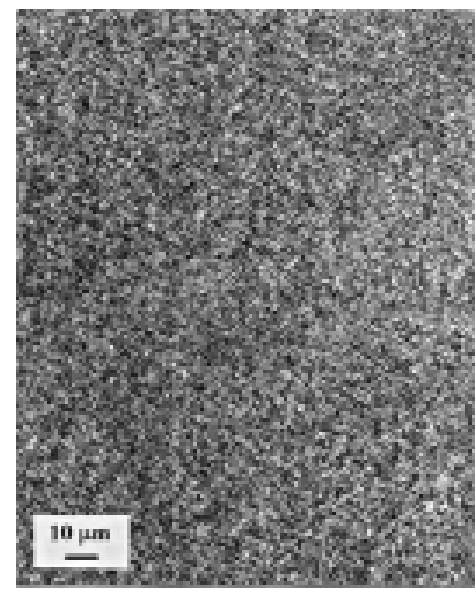

(a)

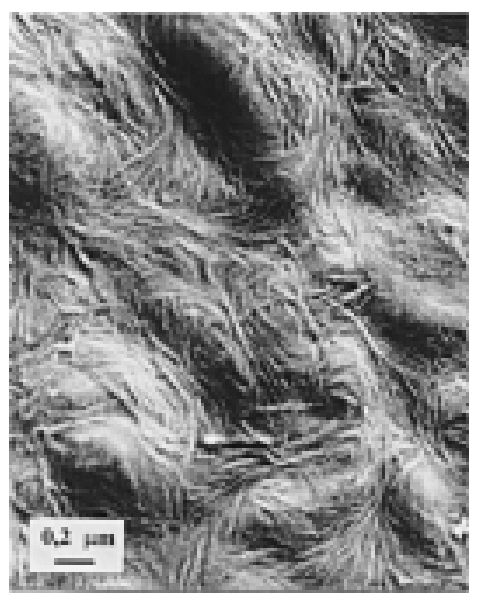

(c) técnicas de fabricação citadas já produzem filmes com algum grau de orientação. Porém, este pode ser aumentado através de estiramento a quente, calandragem ou por "tentering".

A Figura 1 apresenta como exemplo micrografias de um filme comercial de $25 \mu \mathrm{m}$ de espessura, produzido por moldagem a sopro pela Benberg Folien $\mathrm{GmbH}$ na Alemanha. A estrutura morfológica deste filme se apresentou fina demais quando observada por microscopia ótica com luz polarizada, Figura 1(a). No microscópio eletrônico, no entanto, foi revelada uma estrutura de pequenos aglomerados, Figura 1(b) e (c), formados e intermeados por lamelas não orientadas de 10 a $20 \mathrm{~nm}$ de espessura. Com estas amostras de PVDF em forma de filmes semi-finos, o MEVBV conseguiu manter uma boa definição das lamelas até grandes aumentos, sendo que as primeiras instabilidades nas imagens foram observadas a $80.000 X$, Figura 1(d), provavelmente causadas pelo carregamento do filme devido ao feixe eletrônico.

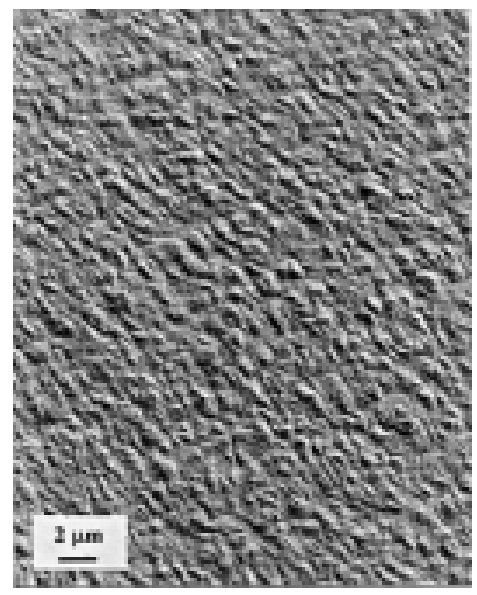

(b)

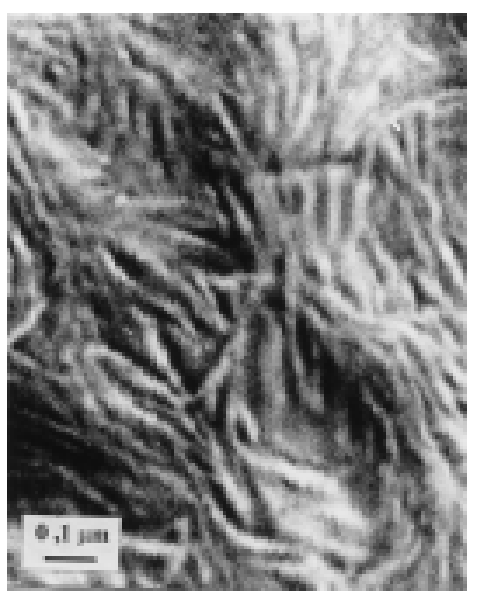

(d)

Figura1. Estrutura de um filme comercial de PVDF produzido por moldagem a sopro. Microscopia ótica de luz polarizada em (a), microscopia eletrônica em (b), com resolução lamelar em (c) e (d). 


\section{Morfologia de Filmes $\alpha$ e $\beta$ obtidos por Solução}

Tanto a morfologia como as fases presentes nos filmes de PVDF dependeram da temperatura de cristalização. A Figura 2 apresenta a estrutura de um filme de PVDF com $6 \mu \mathrm{m}$ de espessura, obtido a partir de solução em DMFe cristalizado a $70{ }^{\circ} \mathrm{C}$. A fase dominante, nesta temperatura, foi a $\beta$, conforme constatado por espectroscopia no infravermelho e difração de raios- $X^{8}$. Pequenos "grãos" visíveis ao nível de microscopia ótica, Figura 2(a), se revelaram no MEVBV como esferulitos numa estrutura de elevada porosidade, Figura 2(b), provavelmente causada pela baixa taxa de evaporação do solvente. A Figura 2(c) apresenta um aspecto interessante desta estrutura em forma de fibrilas orientadas, crescidas sob ação de forças de tensão superficial que se manifestaram entre os esferulitos durante o processo de solidificação. $\mathrm{Na}$ ausência destas forças, predomina a morfologia lamelar não orientada observada na superfície livre dos esferulitos, Figura 2(d). A Figura 3 apresenta a morfologia de uma amostra cristalizada a partir de solução em DMF

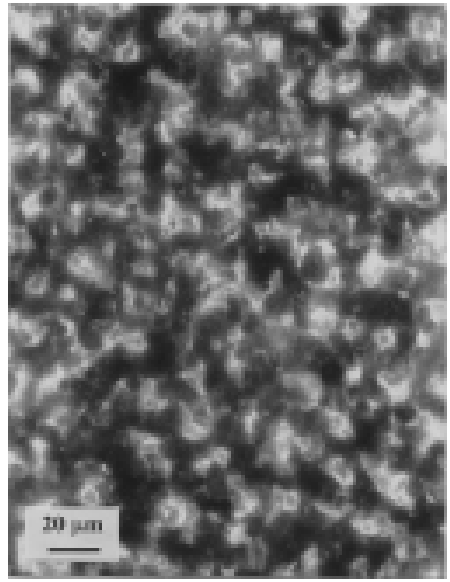

(a)

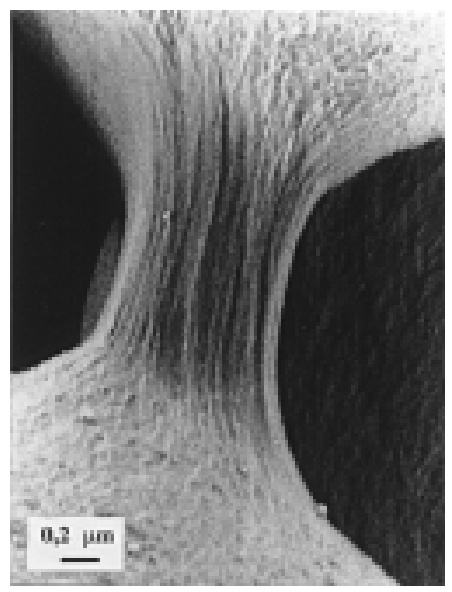

(c) a $140{ }^{\circ} \mathrm{C}$. Neste caso, a fase cristalina predominante foi a alfa, também verificada por espectroscopia no infravermelhoe por difração de raios- $X^{8}$. A estrutura é formada por esferulitos pequenos, Figura 3(a), porém praticamente isenta de porosidade. Detalhes desta estrutura podem ser observados nas Figuras 3(b) e 3(c), onde nota-se um emaranhado de lamelas, semelhante ao observado nas superfícies dos esferulitos da fase $\beta$, Figura 2(d). Foi registrada também a existência de uma estrutura anelada, Figura 3(d), confirmando as observações feitas em um trabalho anterior, onde foi verificado que a cristalização por solução do PVDF acima de $130{ }^{\circ} \mathrm{C}$ começa a produzir esferulitos anelados ${ }^{8}$.

\section{Morfologia Esferulítica das Fases $\alpha$ e $\gamma$}

Trabalhos recentes sobre a cristalização do PVDF por solução ou a partir do fundido apresentaram dois aspectos interessantes a respeito da morfologia esferulítica ${ }^{4,8}$ : Enquanto a fase $\alpha$ dominou em filmes cristalizados a $\mathrm{T}<160^{\circ} \mathrm{C}$, temperaturas acima de $160{ }^{\circ} \mathrm{C}$,

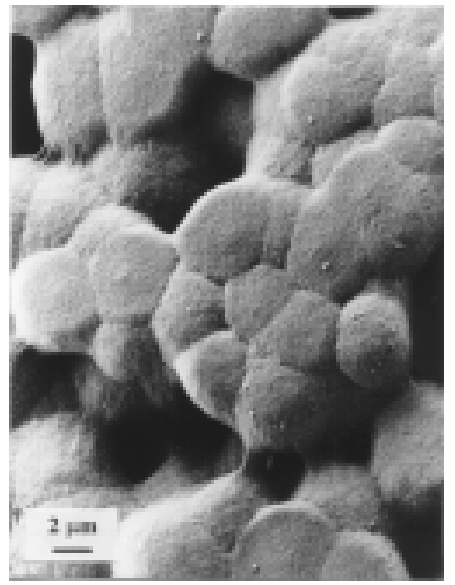

(b)

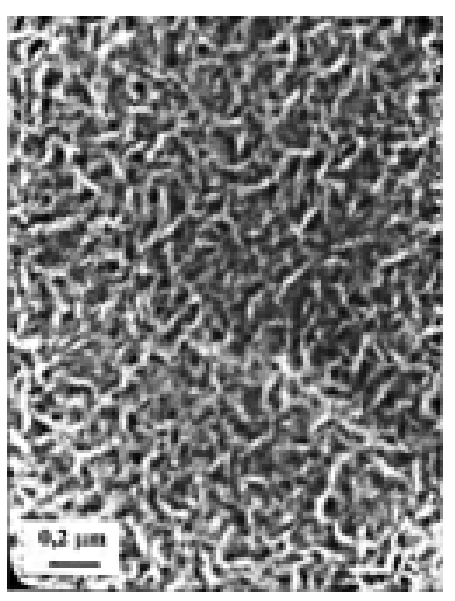

(d)

Figura 2. Estrutura de um filme de $\beta$-PVDF cristalizado a partir de solução a $70{ }^{\circ} \mathrm{C}$. Microscopia ótica de luz polarizada em (a), microscopia eletrônica com estrutura esferulítica em (b) e resolução lamelar em (c) e (d). 
aliadas a tempos mais longos ( $\mathrm{t}>4 \mathrm{~h})$, favoreceram a formação de uma estrutura mista, constituída por $\alpha+\gamma$. Além disto, e em função da temperatura de cristalização, formaram-se esferulitos não anelados $\left(\mathrm{T}<130^{\circ} \mathrm{C}\right)$, aneladas $\left(130{ }^{\circ} \mathrm{C}<\mathrm{T}<150{ }^{\circ} \mathrm{C}\right)$, ou uma mistura de esferulitos anelados, não anelados e parcialmente anelados $\left(\mathrm{T}>150{ }^{\circ} \mathrm{C}\right)$. A origem dessas formas diferenciadas de esferulitos no PVDF continua ser objeto de discussão na literatura, com alguns autores sugerindo que elas dependeriam da fase cristalina com que as lamelas são formadas ${ }^{9,10}$ : Os esferulitos anelados seriam formados pela fase $\alpha$, enquanto os esferulitos não anelados estariam associados à fase $\gamma$, ou a uma mistura das fases $\alpha$ e $\gamma^{9}$. A Figura 4 apresenta um exemplo desta estrutura mista, observada em um filme cristalizado por $9 \mathrm{~h}$ a $168^{\circ} \mathrm{C}$. Ao nível do microscópio ótico com luz polarizada, foram encontrados esferulitos anelados, não anelados e parcialmente anelados, Figura 4(a). Quando o mesmo filme foi observado no microscópio eletrônico, foram revelados dois tipos bem diferentes

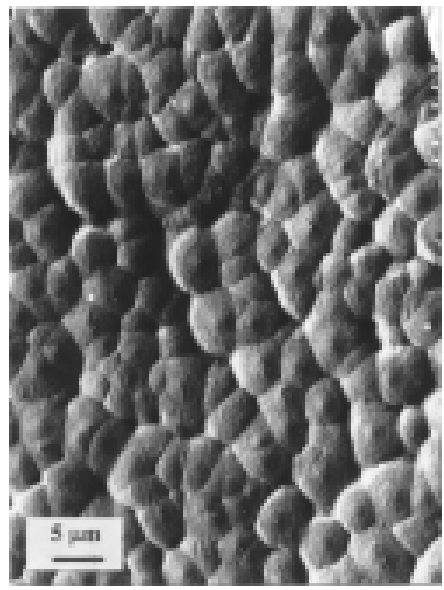

(a)

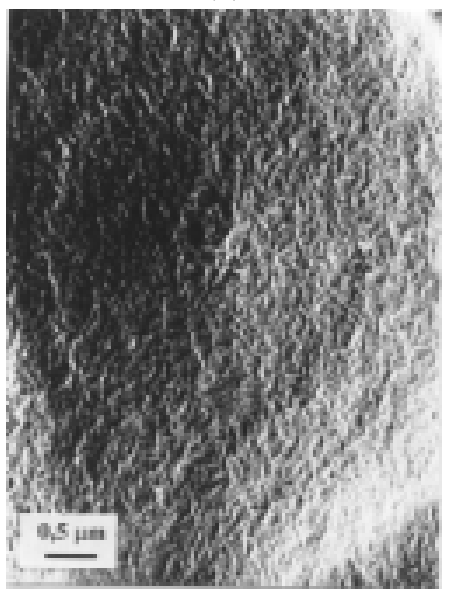

(c) de estrutura lamelar. O primeiro tipo aparece na Figura 4(b), mostrando uma morfologia esferulítica de lamelas comuns, irradiando do centro do esferulito e crescendo essencialmente paralelas à superfície do filme. A Figura 4(c) apresenta a morfologia de outro esferulito, com lamelas exibindo um perfil curvo, semelhante ao observado por Vaughan em amostras de $\gamma-\mathrm{PVDF}^{11}$. Tais diferenças no hábito de crescimento lamelar talvez possam esclarecer a origem dos esferulitos anelados e não anelados. Para tanto, novos estudos estão sendo realizados para localizar no MEVBV os mesmos esferulitos anelados ou não anelados previamente fotografados no microscópio ótico.

\section{Resolução Lamelar nas Interfaces de Compósitos PE/PE}

\section{Transcristalinidade em Compósitos Poliméricos}

Quando fibras são embutidas em polímeros semicristalinos para fins de reforço mecânico,

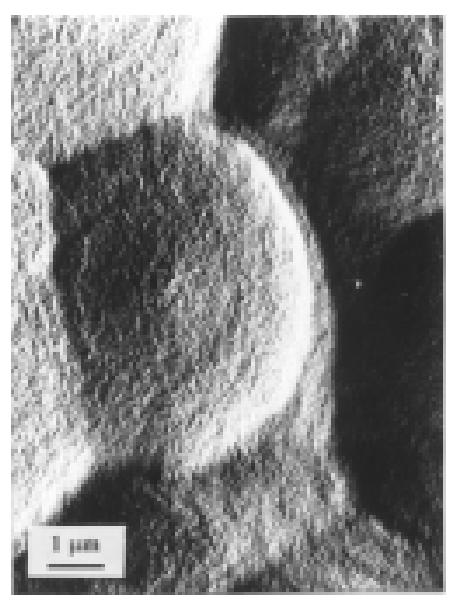

(b)

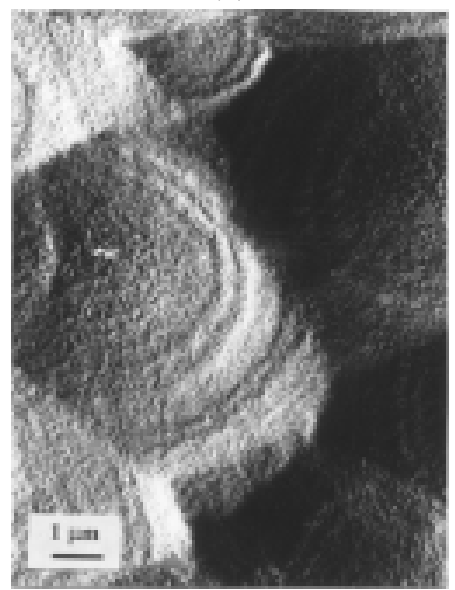

(d)

Figura 3. Estrutura de um filme de $\alpha$-PVDF cristalizado a partir de solução a $140{ }^{\circ} \mathrm{C}$. Microscopia eletrônica com estrutura esferulítica em (a) e resolução lamelar em (b), (c) e (d). 
condições de cristalização podem ser modificadas na região da interface fibra/matriz. Observa-se, com frequência, o fenômeno da transcristalinidade que se refere ao crescimento preferencial de lamelas da matriz em direção perpendicular à fibra, em vez do tradicional crescimento radial que normalmente é responsável pela formação de esferulitos. Embora conhecido há muito tempo ${ }^{12}$, o crescimento transcristalino voltou recentemente a chamar a atenção dos pesquisadores, preocupados em descobrir meios para melhorar a adesão interfacial nos compósitos poliméricos. No entanto, a transcristalinidade nem sempre melhora as propriedades mecânicas ${ }^{13,14}$, e diferentes teorias estão sendo

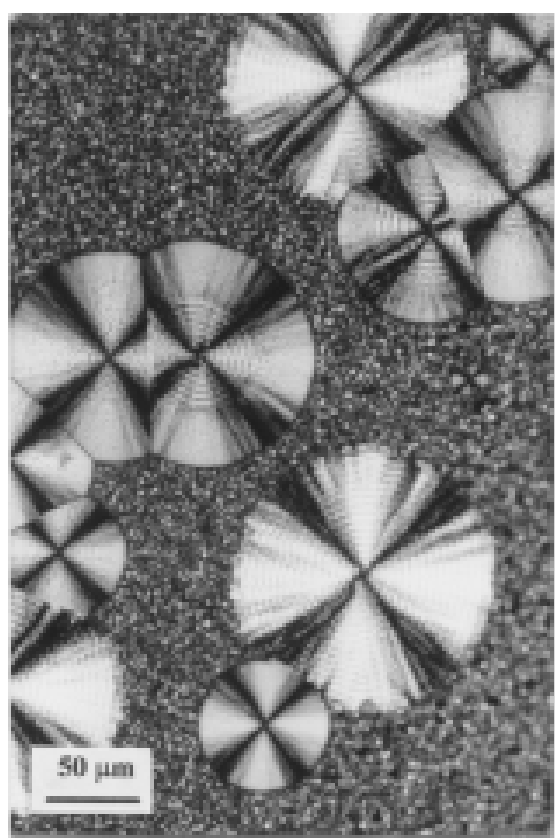

(a) discutidas a respeito de suas causas ${ }^{15-18}$. Existe consenso que muitas das questões abertas poderiam ser resolvidas se as investigações estruturais e morfológicas dos pesquisadores "chegassem diretamente à interface entre fibra e matriz" 17,19 .

\section{Resolução Lamelar em Camadas Transcristalinas de Compósitos PEAD/PEUAPM}

Nos compósitos de polietileno reforçados por fibras de polietileno de ultra-alto peso molecular (PEUAPM) espera-se que a similaridade química entre fibra e matriz possa melhorar a adesão interfacial, uma vez que as fibras de PEUAPM fabricadas

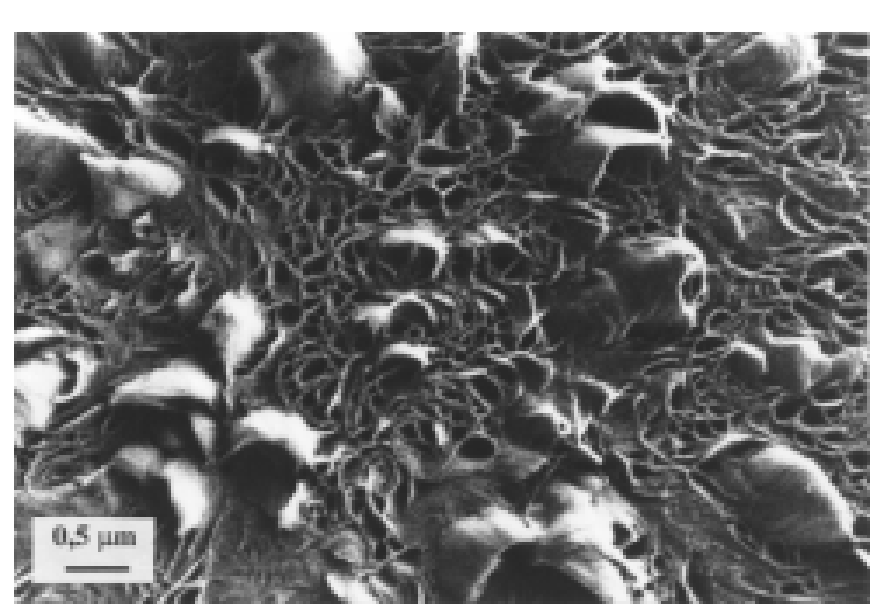

(c)

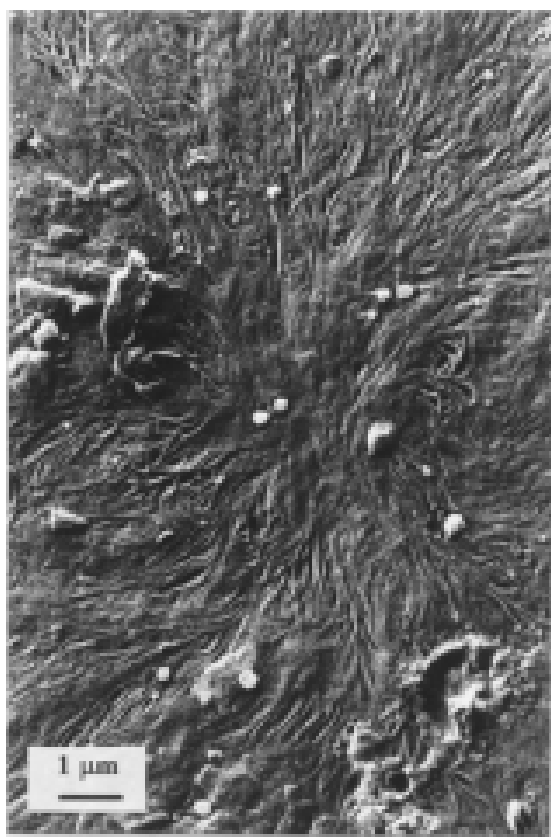

(b) 
pelo processo de "gel-spinning" possuem excelente resistência mecânica (limite de resistência na faixa de 3 GP), mas geralmente apresentam falta de adesão quando utilizadas como material de reforço em outros termoplásticos ou termofixos ${ }^{20,21}$. Microscopia de varredura a baixa voltagem foi utilizada para investigar o crescimento transcristalino em matriz de PEAD.

A Figura 5 apresenta a camada transcristalina que se formou ao longo da fibra de PEUAPM durante ensaio de cristalização em gradiente de temperatura (a frente de cristalização avançava da esquerda para a direita na Figura 5). Verificou-se no microscópio eletrônico que, em determinado trecho da região transcristalina, a fibra tinha chegado à superfície do filme. Nesta região, portanto, podia ser observada a formação inicial da camada transcristalina, Figura 6.
Alternativamente, o surgimento das primeiras lamelas sobre a fibra poderia ser interpretada como início de fusão ou relaxação superficial da sua estrutura fibrilar (cristais "shish" com cadeias extendidas seriam transformadas em cristais "kebab" com cadeias dobradas), fenômeno detectado anteriormente na literatura ${ }^{22}$. Neste caso, porém, não houve início de fusão na superfície da fibra, uma vez que nenhuma lamela foi encontrada longe do filme de PEAD, Figura 7.

Tais observações foram utilizadas para identificar a origem do crescimento transcristalino no sistema PEAD/PEUAPM. Confirmou-se, no presente caso, que as camadas transcristalinas se formaram devido simplesmente à nucleação preferencial ao longo da fibra, enquanto o evento de cristalização epitaxial podia ser excluido, devido à ocorrência de orientações

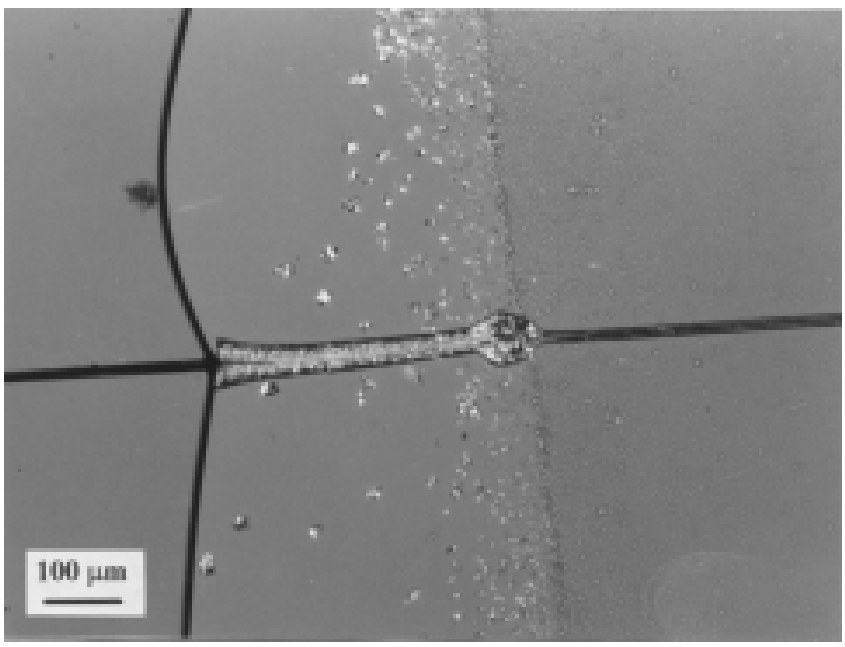

(a)

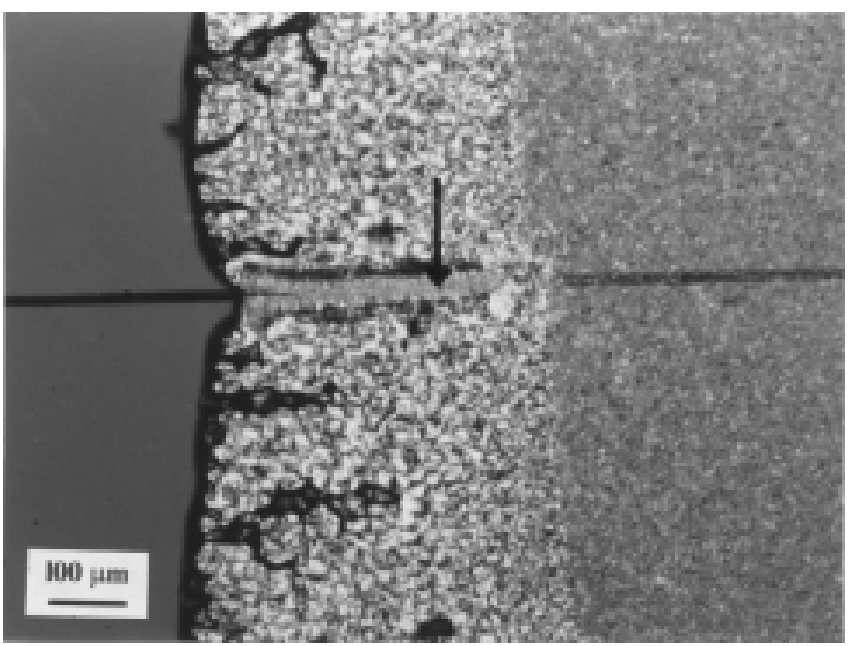

(b)

Figura 5. Transcristalização ao longo de fibra de PEUAPM embutida em PEAD, observada por microscopia ótica. Em (a), temperatura entre 130 e $132{ }^{\circ} \mathrm{C}$. Em (b), após resfriamento à temperatura ambiente. A seta marca região observada por MEV na Figura 6. 


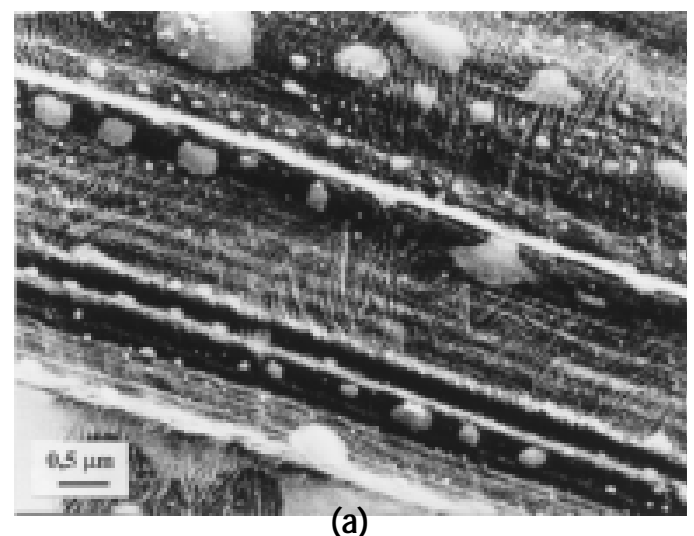

(a)

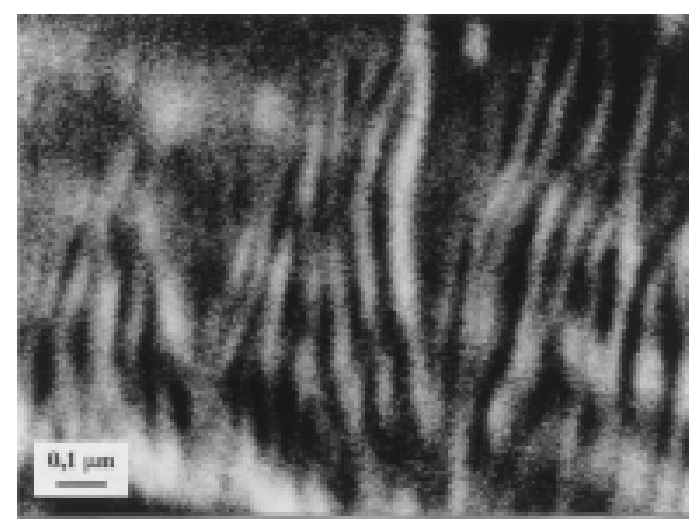

(b)

Figura 6. Estágio inicial do crescimento transcristalino observado por microscopia eletrônica na região marcada pela seta na Figura 5.

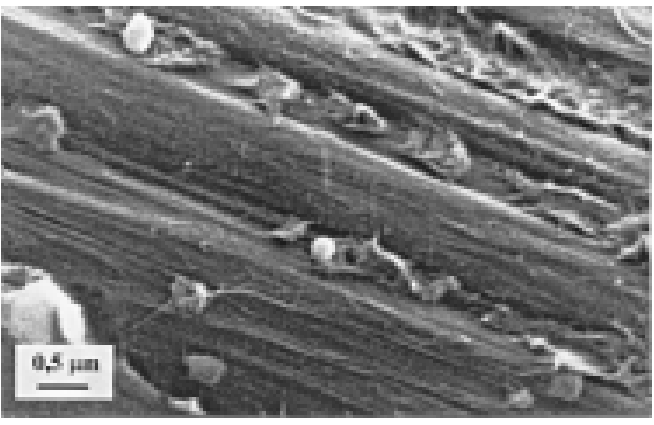

(a)

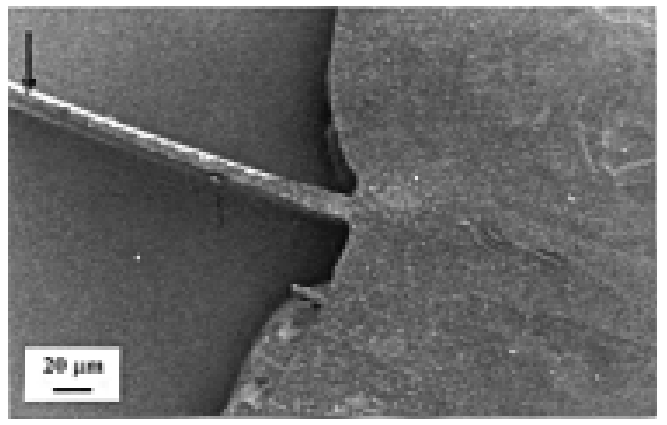

(b)

Figura 7. Fibra de PEUAPM longe do filme de PEAD, sem formação de lamelas. Em (a), micrografia de alta resolução com aumento de 15.000X. Em (b), localização da região que foi fotografada em (a) e que enfrentou temperatura de $131^{\circ} \mathrm{C}$, com aumento de $300 \mathrm{X}$.

muito variáveis das lamelas em relação ao eixo da fibra $^{23}$.

\section{Conclusões}

O novo microscópio eletrônico de varredura a baixa voltagem (MEVBV) promete resolução lamelar para todos os polímeros semicristalinos, sem a necessidade de qualquer preparação especial de amostras. As imagens mantem boa definição das lamelas até aumentos na faixa de 75.000 X, mostrando claramente a presença ou não de orientações preferenciais. A morfologia lamelar que se observa é somente aquela formada na superfície das amostras. Apesar desta restrição, puderam ser reveladas estruturas tipicamente "internas" como camadas transcristalinas em polímeros reforçados por fibras.

\section{Agradecimentos}

Este trabalho recebeu apoio financeiro da Fundação Volkswagen (Volkswagenstiftung) e da Fapesp (Processos 93/4189-5 e 95/9969-4). H.-J. K. e R.G.F. agradecem ao CNPq pelas bolsas de pesquisa
Proc. 300709/93-5 e 301452/91-1, e ao programa RHAE/CNPq pela bolsa de pesquisador visitante, Proc. 46.0543/95-4.

\section{Referências Bibliográficas}

1. Kestenbach, H.-J. e Canevarolo, S.V., Metalurgia \& Materiais 50, 168 (1994).

2. Joy, D.C., J. Microscopy 140, 283 (1985).

3. Goldstein, J.I., Romig Jr., A.D., Newbury, D.E., Lyman, C.E., Echlin, P., Fiori, C., Joy, D.C. e Lifshin, E. Scanning Electron Microscopy and X-Ray Microanalysis, Plenum Press, New York (1992), p.34.

4. Gregorio Jr., R. e Cestari, M.J., J. Polym. Sci. Part B: Polym. Phys., 32, 859 (1994).

5. Broadhurst, M.G., Davis, G.T., McKinney, J.E. e Collins, R.E., Appl. Phys. 49, 4992 (1978).

6. Tashiro, K., Kobayashi, M., Todokoro, H. e Fukuda, E., Macromolecules 13, 691 (1980).

7. Ganster, J. e Geiss, D., Polymer 26, 1825 (1985). 
8. Gregorio Jr., R., Cestari, M., Nociti, N.C.P.S., Lucas, A.A. e Mendonça, J.A., em The Polymeric Materials Encyclopedia: Synthesis, Properties and Applications, CRC Press, Inc. (1995), p.2286.

9. Prest, W.M. e Luca, D.E., J. Appl. Phys. 49, 5042 (1978).

10. Lovinger, A.J., J. Polym. Sci., Polym. Phys. Ed. 18, 793 (1980).

11. Vaughan, A.S., J. Mater. Sci. 28, 1805 (1993).

12. Jenckel, E., Teege, E. e Hinrichs, W., Kolloid Z. 129, 19 (1952).

13. Masouka, M., Int. J. Adhesion Adhesives 1, 256 (1981).

14. Folkes, M.J. e Wong, W.K., Polymer 28, 1309 (1987).

15. Wittmann, J.C. e Lotz, B., Prog. Polym. Sci. 15, 909 (1990).
16. Greso, A.J. e Phillips, P.J., Polymer 35, 3373 (1994).

17. Sukhanova, T.E., Lednicky, F., Urban, J., Baklagina, Y.G., Mikhailov, G.M. e Kudryavtsev, V.V., J. Mater. Sci. 30, 2201 (1995).

18. Varga, J. e Karger-Kocsis, J., Polymer 36, 4877 (1995).

19. Huang, J. e Petermann, J., a ser publicado em Polym. Bull. (1996).

20. Holmes, S. e Schwartz, P., Comp. Sci. Technol. 38, 1 (1990).

21. Tissington, P., Pollard, G. e Ward, I.M., Comp. Sci. Technol. 44, 185 (1992).

22. Mead, T.S. e Porter, R.S., J. Appl. Polym. Sci. 22, 3249 (1978).

23. Kestenbach, H.-J., Loos, J. e Petermann, J., Trabalho apresentado no VI International Macromolecular Colloquium, Gramado, RS, Setembro (1996). 